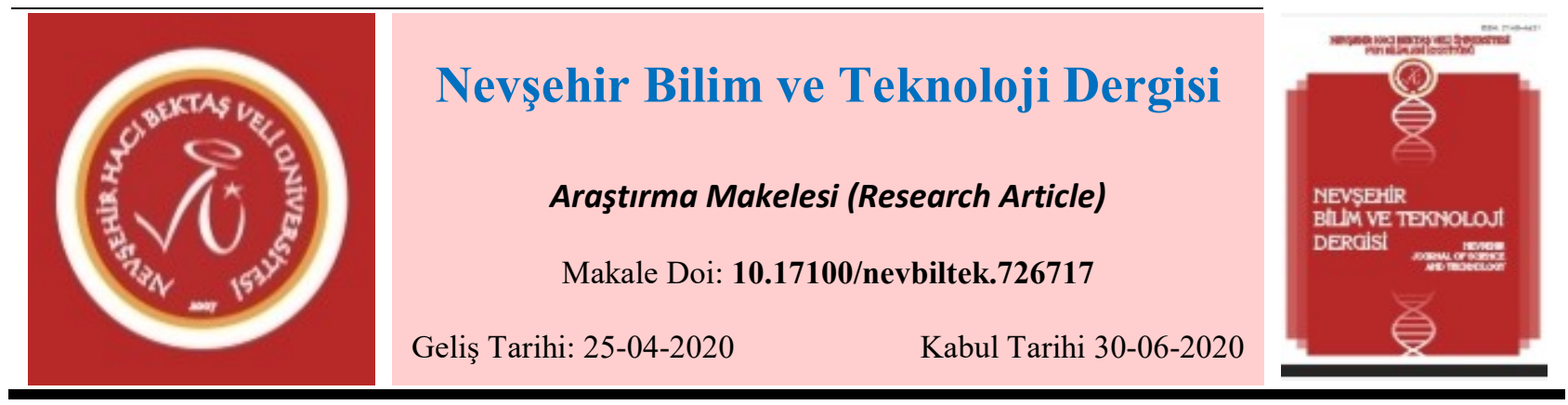

\title{
Nd katkılı Seramik Malzeme ile Kaplanan Bir Dizel Motorda Yanma Karakteristiğinin
}

\author{
Araştırılması 1 \\ Ömer CİHAN ${ }^{1}$, İlker TEMIZER ${ }^{2}$, Mustafa Güven GÖK ${ }^{3}$, Muhammet KARABAŞ ${ }^{4}$ \\ ${ }^{1}$ Hakkari Üniversitesi, Mühendislik Fakültesi, Makine Mühendisliği Bölümü, Hakkari \\ ORCID ID: 0000-0001-8103-3063 \\ ${ }^{2}$ Cumhuriyet Üniversitesi Teknoloji Fakültesi, Otomotiv Mühendisliği Bölümü, Sivas \\ ORCID ID: 0000-0003-1170-3898 \\ ${ }^{3}$ Hakkari Üniversitesi, Mühendislik Fakültesi, Malzeme Bilimi ve Mühendisliği Bölümü, Hakkari \\ ORCID ID: 0000-0002-5959-0549 \\ ${ }^{4}$ Hakkari Üniversitesi, Mühendislik Fakültesi, Malzeme Bilimi ve Mühendisliği Bölümü, Hakkari \\ ORCID ID: 0000-0002-0666-6132
}

Öz

Motorda yanma odası; silindir kapak (kafa) yüzeyi, piston üst yüzeyi ve silindir cidarından meydana gelmektedir. Klasik pistonlu motorlarda çevrimin yanma ve genişleme sürecinde yanma odasını oluşturan bu elemanlar, yüksek sıcaklık ve basınca maruz kalmaktadır. Yanma odası içerisinde gerçekleşen patlama sonucu yanma odası elemanlarının yüzeylerinde korozyon, termal şoklama, aşınma ve yüzeysel deformasyonlara yol açmaktadır. Bu deformasyonları azaltmanın bir yolu da motor parçalarının termal iletkenliği düşük seramik malzemeler ile kaplanmasıdır. Bu kaplamalara termal bariyer kaplama adı verilir. Termal bariyer kaplama ile motorun performans ve veriminde iyileşme meydana gelebilmektedir. Dizel motorlarda soğutmaya giden enerji, açığa çıkan toplam enerjinin \%30 ila \%35'ine tekabül etmektedir. Soğutmaya giden bu enerji diliminin bir kısmı bu yöntem ile faydalı enerjiye (motor çıkış mili gücü) dönüşmesi beklenmektedir.

Bu çalışmada; deney motoru olarak hava soğutmalı, tek silindirli, direkt püskürtmeli, 4 zamanlı ve marşlı bir dizel motoru kullanılmıştır. Bu kapsamda deney motorununum silindir kafası, piston, emme ve egzoz supaplarının yüzeyleri öncelikle HVOF (yüksek hızlı oksi-yakıt püskürtme) yöntemi ile NiCoCrAlY bileşiminde metalik bağ katmanı kaplanmıştır. Ardından da APS (Atmosferik Plazma Sprey) yöntemi ile seramik ara katman olarak CYSZ (Serya-itriya Stabilize Zirkonya) ve seramik en üst katman olarak da $\mathrm{La}_{1.4} \mathrm{Nd}_{0.6} \mathrm{Zr}_{2} \mathrm{O}_{7}$ kullanarak çok katmanlı tasarımda kaplanmıştır. Daha sonra motor tam yük ve farklı motor hızlarında çalıştırılmıştır. Sonuç olarak kaplama ile motorda maksimum silindir için basınç ve ısı salınım oranları tüm hızlarda referans (kaplamasız) motora kıyasla yüksek çıkmıştır. Ayrıca kaplama ile maksimum basıncın üst ölü noktadan daha uzakta meydana geldiği ve yanmanın genişleme sürecine doğru ilerlediği tespit edilmiştir.

Anahtar Kelimeler: Dizel motor, Yanma, Termal bariyer kaplama, Atmosferik plazma sprey (APS).

\section{Investigation of Combustion Characteristics in a Diesel Engine Covered with Nd-doped Ceramic Material}

Abstract

The combustion chamber of the engine consists of the cylinder head, piston top surface and cylinder wall. In conventional reciprocating engines, these elements which form the combustion chamber during the combustion and expansion process of the cycle are exposed to high temperature and pressure. As a result of the explosion in the combustion chamber, corrosion, thermal shock, abrasion and surface deformations on the surfaces of the combustion chamber elements are caused. One way to reduce these deformations is to coating the engine parts with ceramic materials with low thermal conductivity.

\footnotetext{
${ }^{1} \mathrm{Bu}$ makale, 4. International Conference on Material Science and Technology in Kizılcahamam/ANKARA(IMSTEC 2019) sempozyumunda sözlü sunum yapılmıştır.

Sorumlu yazar e-mail: omercihan@hakkari.edu.tr
} 
These coatings are called thermal barrier coatings. The thermal barrier coating can improve the performance and efficiency of the engine. In diesel engines, the energy for cooling corresponds to $30 \%$ to $35 \%$ of the total energy released. Some of this energy fraction for cooling is expected to be converted into useful energy (motor output shaft power) by this method.

The test engine was air cooled, single cylinder, direct injection, 4 stroke and starter diesel engine was used in this study. In the scope of the experiment, the surfaces of the cylinder head, piston, intake and exhaust valves of the test engine are coated with metallic bond layer in the composition of NiCoCrAlY by HVOF (High Velocity Oxygen Fuel) method. Then, it was coated in a multi-layer design using APS (Atmospheric Plasma Spray) method using CYSZ (Ceria Yttria Stabilize Zirkonya) as ceramic interlayer and $\mathrm{La}_{1.4} \mathrm{Nd}_{0.6} \mathrm{Zr}_{2} \mathrm{O}_{7}$ as the top layer. The engine was operated at full load and different engine speeds. As a result, the maximum cylinder pressure and heat release rates in the engine with coating were higher than the reference (uncoated) engine at all speeds. It was also found that the maximum pressure with the coating occurred further away from the top dead center and the combustion proceeded towards the expansion process.

Keywords: Diesel engine, Combustion, Thermal Barrier Coating, Atmospheric Plasma Spray (APS).

\section{Giriş}

Termal bariyer kaplamaları, uçak, denizaltılar ve araçlar gibi yüksek çalışma sıcaklıklarına maruz kalan sıcak parçaları korumak için yaygın olarak kullanılmaktadır. Bu kaplamalar, alt tabaka malzemelerini fiziksel ve kimyasal stabiliteleri nedeniyle agresif sıcak gaz ortamına karşı korur. TBC (Thermal Barrier Coating) sistemi başlangıçta iki farklı katmandan oluşur. Birinci katman metalik bağ kaplama katmanı ve ikinci katman seramik üst katmandır. Metalik bağ tabakası, MCrAlY (M: Ni, Co) bileşimindeki yüksek entropi süper alaşımlarından üretilir ve metalik substratı, termal olarak büyütülen oksit tabakası oluşturarak yüksek sıcaklıkta oksidasyona karşı korur. Seramik üst tabaka genellikle zirkonya esaslı malzemelerden yapılır ve alt tabaka ile düşük 1sı iletkenliği olan sıcak ortam arasında bir sıcaklık farkı sağlayarak yalıtım görevi görür [1-5].

Genel olarak bakıldığında, motorda 1sı kaybı önlenerek yakıt tüketiminin azaltılması için motor yanma odası elemanlarına termal bariyer kaplamalar yapılmaktadır. Bu kaplama ile motorda egzoz ve soğutma sistemine giden kayıplar azaltılabilir. Ayrıca motorda yanma odası sıcaklığı artacağı için motor verimi de yükselir. Egzoz emisyonları olan CO ve NOx emisyon değerlerinde ise azalma görülür. Çoğu araştırmacı düşük 1sı atımı (Low Heat Rejection - LHR) konusu üzerine birçok çalışma yapmıştır. Motorda termal verim, yanma ve egzoz emisyonları konuları üzerine durulmuştur [6].

Parlak ve arkadaşlarının yaptığı çalışmada; 4 zamanlı, ön yanma odalı, tek silindirli bir Ricardo E6 tip motor kullanılmıştır. Farklı sıkıştırma oranlarının denenebildiği bu motorda düşük 1sı atımı (Low heat rejection-LHR) konseptine sahiptir. LHR motorlar soğutmaya giden enerji kaybını azaltarak faydalı işi artırmaktadır. LHR'nin motorda faydası; düşük özgül yakıt tüketimi, hidrokarbon, is ve karbonmonoksitte azalma, oda basıncındaki artı̧ düşeceği için gürültü de az olduğu söylenebilir. Motorda piston, supap ve silindir kafası $0,15 \mathrm{~mm}$ kalınlığında NiCrAl alaşımlı bağlayıcı katman ve $0,35 \mathrm{~mm}$ kalınlığında $\mathrm{MgO}-\mathrm{ZrO}_{2}$ malzemesi ile kaplanmıştır. Sonuç olarak motorda yapılan bu kaplama ile farklı hız ve kısmi yüklerde standart motora göre yapılan bütün sıkıştırma oranı deneylerinde yanma sıcaklığında artma, tutuşma gecikmesi süresinde azalma ve özgül yakıt tüketiminde azalma görülmüştür [7].

Yapılan bir başka çalışmada ise direkt püskürtmeli bir dizel motorunun silindir kafası 0,15 mm kalınlığında bir NiCrAl malzeme ile bağlayıcı bir katman atılmış ve sonrasında $0,35 \mathrm{~mm}$ kalınlığında bir $\mathrm{CaZrO}_{3}$ bileşeni ile kaplanmıştır. Piston ise $\mathrm{MgZrO}_{3}$ malzemesi ile kaplanmıştır. Kaplamalar plazma sprey yöntemiyle yapıllmıştır. Motor tam yük ve farklı hız aralığında seramik kaplama ile yanma veriminin yükseldiği tespit edilmiştir [8].

Diğer bir çalı̧̧mada ise yanma odası elemanları Alüminyum oksit-Zirkonyum oksit $\left(\mathrm{Al}_{2} \mathrm{O}_{3}-\mathrm{ZrO}_{2}\right)(\%$ 20-80), Alüminyum oksit-Titanyum oksit $\left(\mathrm{Al}_{2} \mathrm{O}_{3}-\mathrm{TiO}_{2}\right)$ (\% 87-13) seramik malzemeleri ile kaplanmıştır. Burada kaplama kalınlığı kadar silindir kapak yüzeyinden talaş kaldırılmıştır (Sıkıştırma oranının etkilenmemesi için). Bu çalışmada, hava soğutmalı, tek silindirli, doğrudan püskürtmeli, 4 zamanlı ve marşlı Solax marka 178FE tipi dizel motorunun yanma odası 
elemanlarının termal bariyer malzemelerle kaplanması ve 1600 1/min ile 3200 1/min hızları arasinda 400 1/min hız aralıklarında ve tam yük şartları altında \% 100 dizel yakıtı ile denenmesi ve termal bariyer kaplamaların motorun egzoz gaz sıcaklığına, egzoz emisyonlarına ve yakıt sarfiyatına etkileri incelenmiştir. Sonuç olarak motor hızına ve kaplamalara bağlı olarak egzoz sıcaklı̆̆ının arttığı ve yakıt sarfiyatında azalma olduğu görülmüştür [9].

Emme-egzoz supapları ve silindir kapağının $\mathrm{MgO}$ içerikli $\mathrm{ZrO}_{2}$ esaslı malzeme ile kaplı olması motor performansı ve yanma üzerine farklı yük ve hızlarda iyileşmeler sağlandığını göstermektedir. Ayrıca silindir kafasının NiCrAlY alaşımlı bir bağ katmanı $(0,15 \mathrm{~mm})$ ile kaplama mukavemetinin arttığı görülmüş̧ür. Üzerine atılan Y2O3-ZrO2 $(0,35 \mathrm{~mm})$ seramik malzemesi ile motorda egzoz emisyonlarında önemli derecede bir azalma görülmüştür [10].

Direkt püskürtmeli bir dizel motorda silindir kapağ $10,15 \mathrm{~mm}$ NiCrAl bağ katmanı ve $0,35 \mathrm{~mm} \mathrm{CaZrO3} \mathrm{seramik}$ malzeme ile kaplanarak motor çalıştırılmıştır. $2400 \mathrm{~d} / \mathrm{d}$ kadar farklı hızlarda düşük, orta ve tam yükte yapılan deneylerde egzoza giden enerji kaybında seramik malzeme ile standart motora göre bir miktar artış görülmüştür. Fakat soğutmaya giden kayıpta önemli oranda seramik kaplı motorda azalma tespit edilmiştir [11].

Tek silindirli dizel motorlarda yanma odası elemanları kaplanarak motor üzerindeki etkilerinin incelenmesi konusu üzerine literatürde birçok çalışma yer almaktadır. Bir dizel motorda silindir kapağının NiCrAlY ile bağ katmanı (150 mikron), üzerine $\mathrm{ZrO}_{2}-\% 8 \mathrm{Y}_{2} \mathrm{O}_{3}$ seramik malzeme ile motorun çalıştırılması standart dizel motora göre; yakıt tüketiminde azalma, motor gücü ve yanma veriminde artış ve çalışma yüzey sıcaklığı $100^{\circ} \mathrm{C}$ kadar düşürüldüğü böylece malzeme ömrünün uzadığı görülmüştür [12].

Başka bir deneysel çalı̧̧mada, Mercedes-Benz OM364A tipi bir dizel motoruna farklı izolasyon seviyelerindeki düşük ısı kayıplı motor uygulamasının etkileri incelenmiştir. Deney motorunun silindir kapağı ve supapları termal bariyer oluşturmak için $\left(\mathrm{Y}_{2} \mathrm{O}_{3}-\mathrm{ZrO}_{2}\right)$ ile kaplanmıştır. Düşük 1sı kayıplı motor uygulaması ile motor testlerinde, özgül yakıt tüketiminde \% 4-7,1 oranında azalma, egzoz gazı sıcaklıklarında \% 3,5-6,8 artış ve hacimsel verimde \% 0,9-2,6 artı̆̆ tespit edilmiştir. Ayrıca motor performansındaki bu pozitif etkilerin deney motorunun izolasyonu ile ilgili olduğu tespit edilmiştir [13].

Direkt püskürtmeli bir dizel motorunda yanma odası elemanları; NiCrAlY bağ katmanlı (0,15 mm kalınlık) ve üzerine $3 \mathrm{Al}_{2} \mathrm{O}_{3}+2 \mathrm{SiO}_{2}$ seramik malzeme ile kaplanmıştır. Böylece fren gücünde $\% 1.8$ oranında artış, özgül yakıt tüketiminde \%1.76 artış, silindir gaz basıncı ve ısı salınım miktarında artış ve \%22 oranında egzoz gaz sıcaklığının arttığı belirlenmiştir [14].

Diğer bir çalışmada yanma odası elemanlarına yapılacak olan termal bariyer kaplama ile motorda malzeme kalitesinin artması ve bunun sonucu uzun ömürlü olması, oksitlenmeye dirençli, termal genleşme katsayısı yüksek, korozyon direnci ve gerilme toleransı yüksek ve termal iletkenliği düşük özellikte yapılacak kaplamalar motor performansı ve yanmayı iyileştirmede önemli kriterler olduğu vurgulanmıştır [15].

Ravikumar ve Senthilkumar'ın yaptı̆̆ kullanılmıştır. Motorda yakıt olarak dizel + Radish metil ester yağı karışımı denenmiştir. Dizel motorda silindir kapağı, supaplar ve piston yüzeyine termal bariyer kaplama yapılmıştır. Kaplanacak yüzeylere 100 mikron NiCrAl bağ katmanı, 450 mikron ise $\mathrm{TiO}_{2}$ ile plazma sprey yöntemi ile kaplanmıştır. Motor $1500 \mathrm{~d} / \mathrm{d}$ sabit hızda 1,02 ile 5,02 kW güç verecek şekilde 5 deney noktasında çalışılmıştır. Sabit hız ve farklı yüklerde, özgül yakıt tüketimi kaplamasız motora göre hafif bir artış olmuştur. Fakat termal bariyer kaplamalı motorda NOx, HC, is ve CO emisyonlarında azalma tespit edilmiştir [16].

Klasik pistonlu motorlarda, toplam ısıl enerjinin \%60'a yakını egzoz ve soğutma sistemindeki kayba gitmektedir. Bu kaybı önlemek için motor yanma odası elemanlarına termal bariyer kaplama uygulanmakta ve bunun ile ilgili deneysel çalışmalar yapılmaktadır. Yapılan bir deneyde; $5.2 \mathrm{~kW}$ gücünde, tek silindirli, su soğutmalı, $661 \mathrm{~cm} 3$ strok hacminde bir dizel motor kullanılmıştır. Farklı yüklerde ( $\% 20, \% 40, \% 60$ ve \%80) ve farklı sıkıştırma oranlarında $(\varepsilon=14, \varepsilon=16, \varepsilon=17.5)$ 
denenmiştir. Motorda supaplar, piston yüzeyi ve silindir kafası $0,35 \mathrm{~mm}$ kalınlığında $\mathrm{CaZrO}_{3}$ seramik malzemesi ile kaplanmıştır. Motor kaplamalı halde farklı yük ve sıkıştırma oranlarında çalıştırıldığında egzoz gaz sıcaklığının arttığı, termal verimi \%2-4 oranında artış, özgül yakıt tüketiminin ise \%2-10 arasında bir azalma görülmüştür [17].

Diğer bir çalışmada ise dizel motorda silindir kafası, piston üst yüzeyi, supaplar ve silindir gömleği nano seramik malzeme olan $\mathrm{Al}_{2} \mathrm{O}_{3}$ ile $0.20 \mathrm{~mm}$ kalınlığında kaplama yapılmıştır. Kaplamalı motorda güç artarken özgül yakıt tüketiminde bir miktar azalma gözlenmiştir [18].

Bu çalışmada, yanma odası parçalarının yüzeyleri öncelikle yüksek hızlı oksi-yakıt püskürtme (HVOF) yöntemi ile NiCoCrAlY bileşiminde metalik bağ katmanı ile kaplanmıştır. Ardından APS yöntemi ile ilk katman olarak CYSZ ve ikinci (en üst) katman olarak da Neodyum (Nd) oksit katkılı $\mathrm{La}_{2} \mathrm{Zr}_{2} \mathrm{O}_{7}\left(\mathrm{La}_{1.4} \mathrm{Nd}_{0.6} \mathrm{Zr}_{2} \mathrm{O}_{7}\right)$ seramik tozları kullanarak çift katmanlı tasarımlarda termal bariyer kaplama katmanları elde edilmiştir. Çalışmada en üst katman olarak $\mathrm{La}_{1.4} \mathrm{Nd}_{0.6} \mathrm{Zr}_{2} \mathrm{O}_{7}$ kullanılmasının sebebi termal iletkenlik değerinin geleneksel kaplama malzemelerinden daha düşük olması ve ilk katman olarak da CYSZ kullanılmasının sebebi ise daha yüksek termal genleşme katsayısına sahip olması nedeniyledir. Motor deneylerinde öncelikle standart olarak kaplamasız motor, sonra da kaplanmış parçalar ile motor çalıştırılmıştır. Kaplamanın silindir basıncı ve ısı salınım oranı üzerindeki etkileri incelenmiştir. Bu çalışmanın amacı, atmosferik plazma spreyi ile üretilen düşük termal iletkenlikteki lantan zirkonat bazlı kaplamaları kullanarak yanma odasında 1sı kaybını önlemektir. Böylece motorun performansı ve verimliliği artırılmak istenmiştir.

\section{Deneysel Çalışma}

$\mathrm{Bu}$ çalışma, tek silindirli, hava soğutmalı, dört zamanlı direkt püskürtmeli Antor 3LD510 dizel motor kullanılmıştır. Motorun silindir kapağı, piston ve supap yüzeyleri öncelikle yüksek hızlı oksi-yakıt püskürtme (HVOF) yöntemi ile metalik bağ katmanı ve ardından da Atmosferik Plazma Sprey (APS) yöntemi ile seramik kaplama (Termal Bariyer Kaplama) malzemeleri ile kaplanmıştır. Seramik üst katmanlarda çift katmanlı tasarım kullanılmıştır. İlk katman CYSZ (serya-itriya stabilize zirkonya) ikinci katman ise Neodyum (Nd) oksit katk1l1 $\mathrm{La}_{2} \mathrm{Zr}_{2} \mathrm{O}_{7}\left(\mathrm{La}_{1.4} \mathrm{Nd}_{0.6} \mathrm{Zr}_{2} \mathrm{O}_{7}\right)$ olacak şekilde tasarımlar yapılmıştır. $\mathrm{La}_{1.4} \mathrm{Nd}_{0.6} \mathrm{Zr}_{2} \mathrm{O}_{7}$ tozu Auer-Remy GMBH (Hamburg-Almanya) firmasından, CYSZ ve bağ katmanı tozları ise Sulzer Metco (sırasıyla AMDRY997 ve Metco 205NS) firmasından temin edilmiştir. Kaplamaların üretimine yönelik HVOF ve APS yöntemi ile detaylı parametreler ve bilgiler daha önceki çalışmamızda verilmiştir [19]. Üretilen kaplamaların kesit mikro yapısı Şekil 1'de verilmiştir. Bu milroyapıdan anlaşılacağı üzere seramik en üst katman (açık renkli katman) $\mathrm{La}_{1.4} \mathrm{Nd}_{0.6} \mathrm{Zr}_{2} \mathrm{O}_{7}$ iken alt katman (koyu renkli katman) CYSZ şeklindedir.

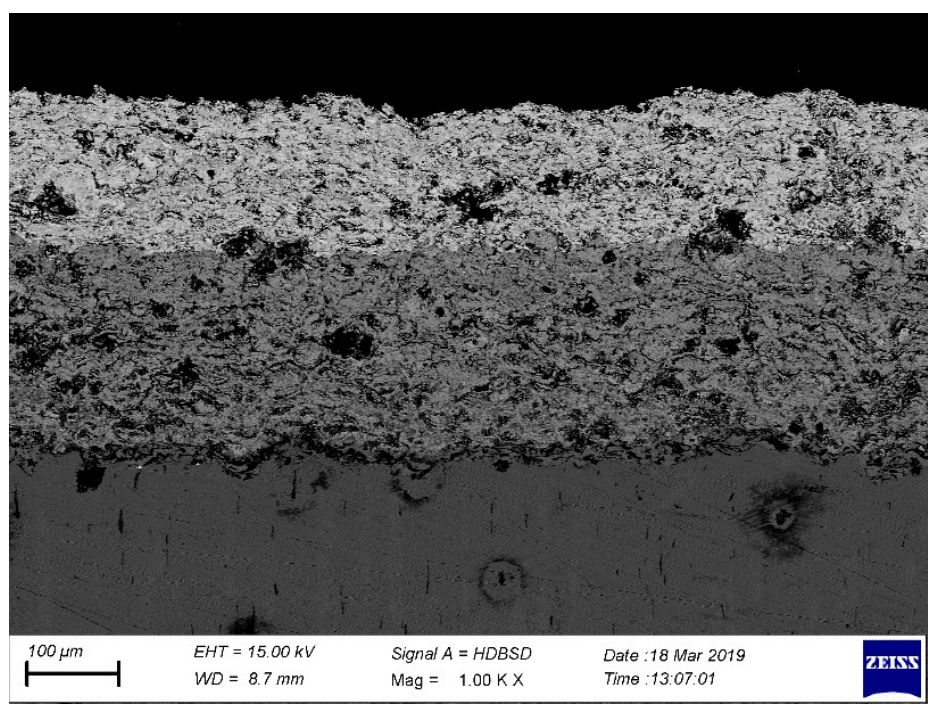


Şekil 1. Üretilen termal bariyer kaplamaların kesit mikro yapısı.

Motor deneyleri tam yükte ve 1200, 1600 ve 2000 d/d motor hızlarında gerçekleştirilmiştir. Direkt enjeksiyonlu dizel motor elektrik dinamometresi ile kontrol edilmiştir. Deney düzeneğinin şematik gösterimi Şekil 2'de verilmiştir ve deney motorunun teknik özellikleri Tablo 1'de verilmiştir. Motorun yanma analizi deneysel olarak incelenmiştir. Yanma analizleri, silindir kafasına yerleştirilmiş bir Optrand fiber optik basınç sensörü ve krank miline bağlı bir Enkoder ile yapılmıştır. Yanma analizi için, her test noktasında 200 çevrim toplanmıştır. Silindir içi basınç ve 1sı salınım oranı, 200 çevrimin ortalaması alınarak kaydedilmiştir.

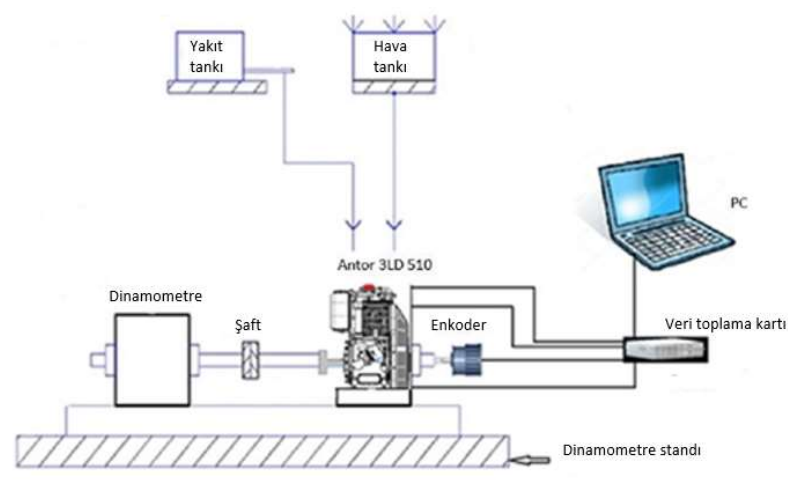

Şekil 2. Deney düzeneği

Tablo 1. Deney motorunun teknik özellikleri

\begin{tabular}{lc}
\multicolumn{2}{c}{ Motor Teknik Özellikleri } \\
4- zamanlı, direkt \\
Motor Tipi & 1 \\
enjeksiyonlu dizel motor & \\
Silindir Sayısı & 510 \\
Silindir Hacmi $\left(\mathrm{cm}^{3}\right)$ & $85 \times 90$ \\
ÇapxStrok (mm x mm) & $17,5: 1$ \\
Sikıştırma Oranı & $8,8 @ 3000$ \\
Maksimum Güç $(\mathrm{kW})$ & $32,8 @ 1800$ \\
Maksimum Tork $(\mathrm{Nm})$ & \\
\hline
\end{tabular}

\section{Sonuçlar ve Tartışma}

Çalışmada referans motorun yanma odası elemanları, deneysel olarak çok katmanlı Lantanyum zirkonat esaslı Nb katkılı La1.4Nd0.6Zr2O7 seramik kaplama ile karşılaştırılmıştır. Deneyler tam yükte ve farklı motor hızlarında (1200, 1600, ve $2000 \mathrm{dev}$ / dak) yapılmıştır. Deneysel çalışmada, kaplanmış yanma odası elemanlarının oluşturduğu yanma odası basıncı ve ısı salınım oranının krank açısına göre değişim parametrelerinin etkileri incelenmiştir. Yanma odası basıncının, referans yanma odası elemanının krank mili açısına ve farklı motor hızlarında kaplanmış yanma odası elemanına göre değişimi Şekil 3 'te gösterilmiştir. Kaplanmış yanma odası elemanlarının maksimum basınçları tüm motor hızlarında referans motordan daha yüksek çıkmıştır. Ek olarak, kaplamadaki maksimum basınçlar Üst ölü noktadan (ÜÖN) daha uzakta elde edilmiştir. Bu durum referans ve kaplanmış elemanların maksimum basınç ve hangi krank mili açısında elde edildiği Tablo 2'de ifade edilmiştir. Yanma odası elemanlarının kaplanmasından sonra, Şekil 3'te yanmanın genişleme zamanına doğru devam ettiği görülmüştür. Kaplanmış oda ile yanma gecikmiştir. Bu durumun ana nedeni, kaplamalı yanma odasındaki sıkıştırma darbesinde ortalama akış hızında azalma ve türbülans yoğunluğudur. Böylece alev hızı 
azalmıştır. Ayrıca, yanmanın genişleme sürecine doğru ilerlediği düşünülmektedir. Referans motorda, ağırlık merkezindeki yanma merkezi ÜÖN'ye daha yakın ve bu pozisyon ile yanma odasındaki alev sönme alanı büyümüştür. Öte yandan, yanma sürecinde yüksek hızlarda bir dalgalanma olmuştur. $\mathrm{Bu}$ dalgalanma, optik sensörün devirleri arasındaki basınç farkından kaynaklanmaktadır.
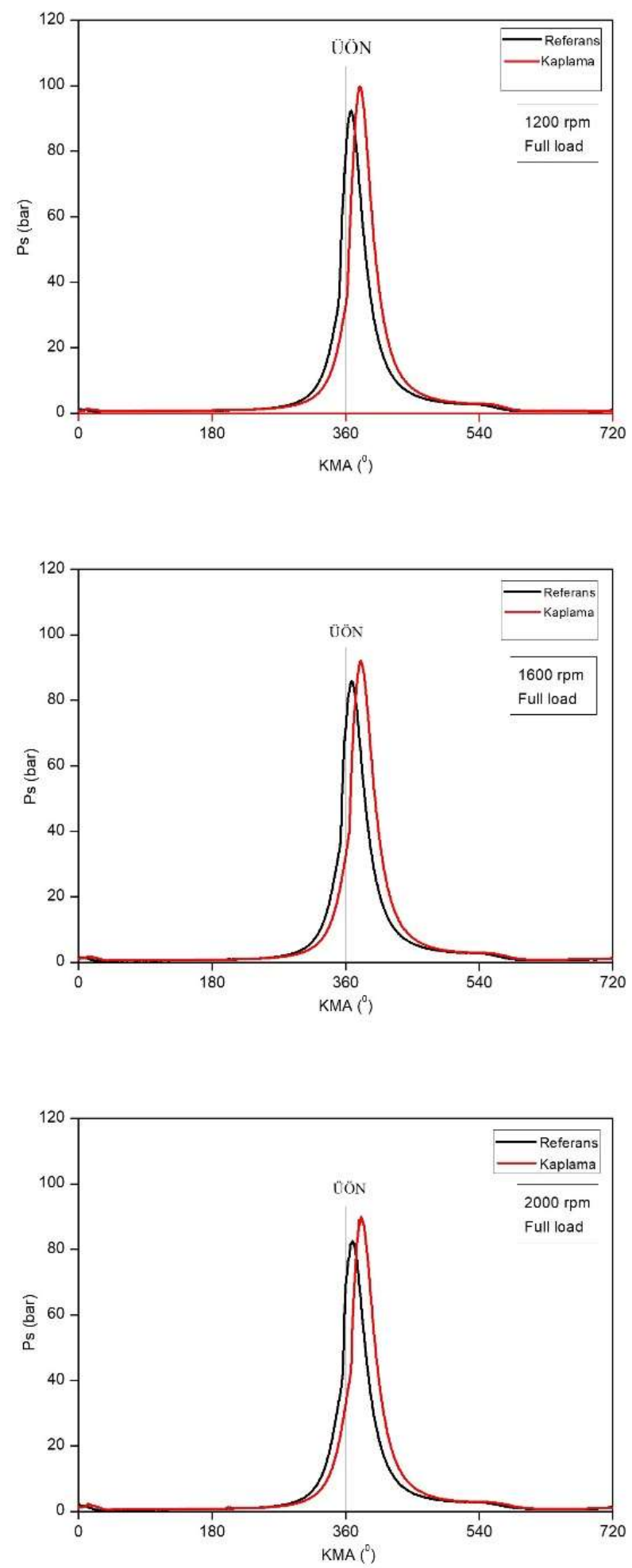

Şekil 3. Farklı motor hızlarında referans ve kaplanmış yanma odası elemanlarının krank mili açısına göre basınç değişimi. 
Nevşehir Bilim ve Teknoloji Dergisi (2019), 9 (IMSTEC Özel Sayı),69-78

\begin{tabular}{cccc}
\hline $\mathbf{n ~ ( d / d )}$ & Terim & Referans & Kaplama \\
\hline 1200 & $\mathrm{P}_{\text {maks }}($ bar) & 92,311 & 99,63 \\
1200 & KMA $\left(^{(}\right)$ & 367 & 379 \\
1600 & $\mathrm{P}_{\text {maks }}($ bar $)$ & 85,83 & 92,071 \\
1600 & KMA $\left({ }^{\circ}\right)$ & 368 & 380 \\
2000 & $\mathrm{P}_{\text {maks }}($ bar $)$ & 82,548 & 89,859 \\
2000 & KMA $\left(^{\circ}\right)$ & 369 & 381 \\
\hline
\end{tabular}

Kaplanmış ve referans yanma odalarına ait ani ısı salınım oranları Şekil 4'te verilmiştir. Kaplamanın, referans yanma odasına kıyasla maksimum ısı salınım oranı tüm hızlarda oldukça yüksektir. Ek olarak, kaplamadaki maksimum 1S1 salınım oranları ÜÖN'den daha uzakta elde edilmiştir. Bu durum silindir içi basınç grafiğine yakındır.

Çalışmada seramik termal bariyer kaplama katmanlarında ilk (ara) katman oalarak kullanılan CYSZ kaplama sistemin termal çevrim ömrünü arttırırken; Nd oksit ile katkılı lantan zirkonat kaplamanın termal iletkenlik değerini düşürmüştür. Bu durum, kaplamaların termal döngü performansını arttırmıştır. Ayrıca, kaplamaların düşük 1sı iletkenliği motorda 1sı kaybını azaltmıştır.

Püskürtme avansı deneyde sabit tutulmuştur. Referans yanma odası için yanmanın daha önce başladığı ve kısa sürede tamamlandığı söylenebilir. Kaplanmış yanma odada ise yanmanın daha sonra ve yavaş bir şekilde başladığı ve yanma işleminin genişleme sürecine doğru uzadığı görülmüştür.

Genel olarak, motordaki 1sı kaybını önleyerek yakıt tüketimini azaltmak için motor yanma odası elemanlarına termal bariyer kaplamaları yapılmıştır. Egzoz ve soğutma sistemi kayıplarının motorda bu kaplama ile bir miktar önlendiği görülmüştür. Ayrıca, yanma odasının basıncı ve sıcaklığı arttıkça motor verimi artmıştır. Isı salınım oranı; silindir içi basınç, hacim ve özgül ısı kullanılarak hesaplanmıştır.

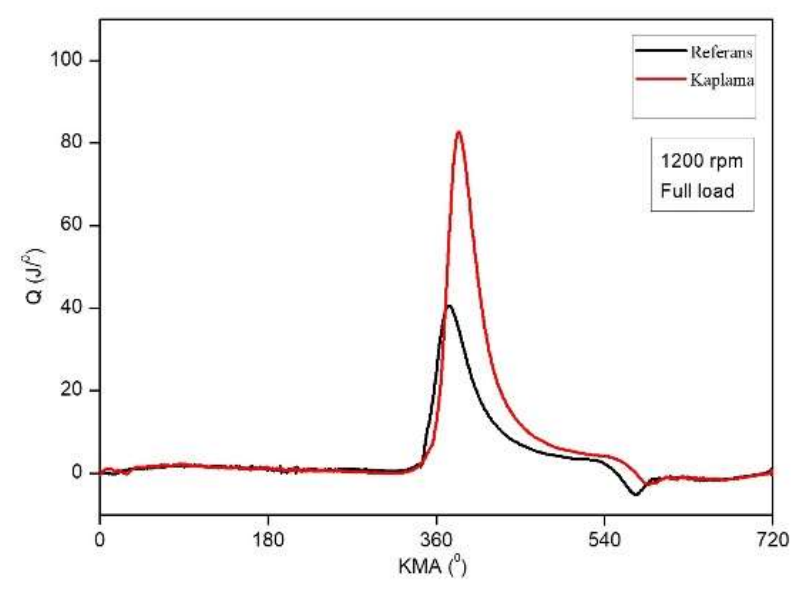



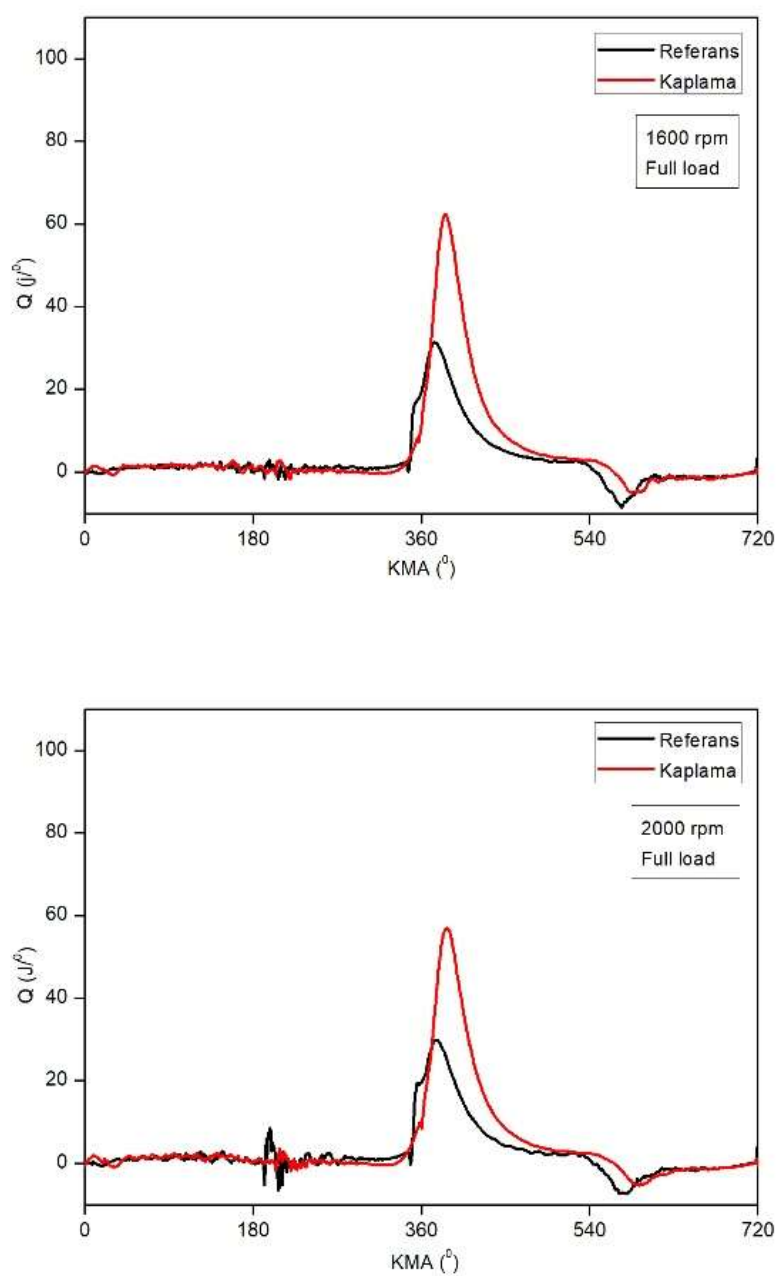

Şekil 4. Farklı motor hızlarında referans ve kaplanmış yanma odası elemanları için krank miline bağlı anlık ısı salınım oranları.

\section{Tartışma ve Sonuç}

Bu çalışmada, HVOF yöntemi ile NiCoCrAlY bileşiminde metalik bağ katmanı ve ardından da APS yöntemi ile seramik ara katman olarak CYSZ ve seramik en üst katman olarak da Nd katk1lı $\mathrm{La}_{1.4} \mathrm{Nd}_{0.6} \mathrm{Zr}_{2} \mathrm{O}_{7}$ kullanarak çok katmanlı tasarımdaki termal bariyer kaplamalar başarıyla üretilmiştir. Deneyler Antor marka 3LD510 model tek silindirli ve direkt püskürtmeli bir dizel motorunda yapılmıştır. 1200, 1600 ve $2000 \mathrm{~d} / \mathrm{d}$ motor hızlarında ve tam yük koşulunda çalışılmıştır. Motorun yanma odası elemanları olan silindir kapağı (supaplar dahil) ve piston üst yüzeyi kaplanmıştır. Krank mili açısına bağlı olarak silindir içi basınç ve ısı salınım oranına kaplamanın etkisi araştırılmıştır. Yapılan çalışmada kaplanmış yanma odası ile tüm hızlarda silindir içi maksimum basınç referans (kaplamasız) motora göre daha yüksek çıkmıştır. Ayrıca maksimum basınç kaplanmış yanma odası ile ÜÖN 'dan daha uzakta ve yanmanın genişlemeye doğru kaydığı görülmektedir. Bu durumun ana nedeni, kaplamalı yanma odasındaki sıkıştırma darbesinde ortalama akış hızında azalma ve türbülans yoğunluğudur. Böylece alev hızı azalmıştır. Referans motorda, yanmanın ağırlık merkezi ÜÖN 'ye daha yakın ve bu pozisyon ile yanma odasındaki alev sönme alanı büyümüştür. Kaplamadaki maksimum 1sı salınım oranları ÜÖN'den daha uzakta elde edilmiştir. Bu durum silindir içi basınç grafiğine yakındır.

Çalışmada seramik üst katman için kullanılan çok katmanlı tasarım sayesinde, kaplama sisteminin hem termal iletkenliği düşmüş ve hem de termal çevrim performansı iyileşmiştir. Ayrıca, kaplamaların düşük 1sı iletkenliği motorda 
1Sı kaybını azaltmıştır. Silindir içi basıncın yüksek olması oda sıcaklığını da yükseltir. Dolayısıyla birim hacimden elde edilen motor gücünün arttı̆̆ı söylenebilir.

\section{Teşekkür}

$\mathrm{Bu}$ çalışma, Hakkari Üniversitesi Bilimsel Araştırma Projeler birimi FM18BAP12 numaralı proje tarafindan desteklenmiştir.

\section{Kaynaklar}

[1]. Nicoll A.R., Gruner H., Prince R., Wuest G., "Thermal Spray Coatings for High Temperature Protection” Surface Engineering, 1, 1, 59-71, 1985.

[2]. Darolia R., "Thermal barrier coatings technology: critical review, progress update, remaining challenges and prospects" International Materials Reviews, 58 (6): 315-348, 2013.

[3]. Dhomme S., Mahalle A.M., “Thermal barrier coating materials for SI engine” Journal of Materials Research and Technology, 8, 1, 1532-1537, 2019.

[4]. Yin Y., Qi R., Zhang H., Xi S., Zhu Y., Liu Z., "Microstructure design to improve the efficiency of thermal barrier coatings" Theoretical \& Applied Mechanics Letters, 8, 1, 18-23, 2018.

[5]. Taymaz İ., "The effect of thermal barrier coatings on diesel engine performance" Surface and Coating Technology, 201, 9-11, 5249-5252, 2007.

[6]. Domakonda V.K., Puli R.K., “Application of Thermal Barrier Coatings in Diesel Engines: a Review” Energy and Power, 2, 1, 9-17, 2012.

[7]. Parlak A., Yasar H., Sahin B., "Performance and exhaust emission characteristics of a lower compression ratio LHR Diesel engine" Energy Conversion and Management, 44, 1, 163-175, 2003.

[8]. Uzun A., Cevik I., Akcil M., "Effects of thermal barrier coating on a turbocharged diesel engine performance" Surface \& Coatings Technology, 116-119, 505-507, 1999.

[9]. Gurbuz H., Gokkaya H., “An experimental study on the effects of the thermal barrier plating over engine fuel consumption exhaust temperature and emissions" Pamukkale University Journal of Engineering Sciences, 20, 1, 15-19, 2014.

[10]. Ciniviz M., Salman M.S., Canlı E., Köse H., Solmaz Ö., "Ceramic coating applications and research fields for internal combustion engines" Ceramic Coatings-Applications in Engineering, 195-234, 2012.

[11]. Taymaz I., Cakir K., Gur M., Mimaroglu A., "Experimental investigation of heat losses in a ceramic coated diesel engine" Surface \& Coatings Technology, 169-170: 168-170, 2003.

[12]. Azadi M., Baloo M., Farrahi G.H., Mirsalim S.M., “A review of thermal barrier coating effects on diesel engine performance and components lifetime” International Journal of Automotive Engineering, 3, 1, 305-317, 2013.

[13]. Haşimoğlu C., Ciniviz M., Salman M.S., "Performance Evaluation of A Low Heat Rejection Diesel Engine for Different Insulation Levels” Pamukkale University Journal of Engineering Science, 16, 1, 87-94, 2010.

[14]. Patond S.B., Chaple S.A., Shrirao P.N., Shaikh P.I., "Comparative Study of Performance and Combustion Characteristics of Conventional and Low Heat Rejection (Mullite Coated) Diesel Engines" IOP Conf. Series: Materials Science and Engineering, 46, 1-9, 2013.

[15]. Turgut İ., Gumus M., Akçay M., "Thermal barrier coatings for diesel engines" International Scientific Conference 19-20 November, 173-177 p, Gabrovo, 2010. 
Nevşehir Bilim ve Teknoloji Dergisi (2019), 9 (IMSTEC Özel Sayı),69-78

[16]. Ravikumar V., Senthilkumar D., "Reduction of NOx emission on NiCrAl-Titanium Oxide coated direct injection diesel engine fuelled with radish (Raphanus sativus) biodiesel" Journal of Renewable and Sustainable Energy, 5, 6, 1-11, 2013.

[17]. Chandrashekar T.K., Rajshekar C.R., Kumar R.H., "An experimental study on the effect of thermal barrier coating on diesel engine performance" International Journal of Innovative Research in Science, Engineering and Technology, 2, 8, 3554-3562, 2013.

[18]. Mohamedmusthafa M., Sivapirakasam S.P., Udayakumar M., Balasubramanian K.R., "Effects of Al2O3 coating on diesel engine performance, combustion, and emission characteristics fueled by pongamia methyl ester and its blends with diesel” Environmental Progress \& Sustainable Energy, 31, 1, 147-156, 2012.

[19]. Gök, M, Cihan, Ö , Karabaş, M, Temizer, İ . "Katkılı La2Zr2O7 Esaslı Seramiklerin Termal Bariyer Kaplama Olarak Kaplanabilirliğinin Araştırılması” Journal of the Institute of Science and Technology, 10, 456-464, 2020. 